\title{
Disruption of fixed-ratio performance as a function of reinforcement delay*
}

\section{MARSHA A. BULLOCK and RALPH W. RICHARDS Colorado State University, Fort Collins, Colo. 80521}

After a pigeon was trained on a fixed-ratio 50 schedule, a delay of reinforcement was introduced and gradually increased to $30 \mathrm{sec}$. Dependent measures of the bird's performance were the duration of the pause after reinforcement and the time required to complete the ratio. The mean and standard deviation of both measures increased, suggesting that the 30-sec delay disrupted fixed-ratio performance.

Skinner (1938) hypothesized that a delay in the presentation of a reinforcer would reduce the effectiveness of that reinforcer. This idea was supported by his study (Skinner, 1938), which showed that the introduction of a delay in reinforcement reduced the rate of responding of a rat trained on a continuous reinforcement (CRF) schedule. To a certain extent, the effects of delay can be ameliorated by the previous experience of the organism. For example, Ferster (1953) found that responding was more likely to be maintained at predelay rates if the delay was introduced gradually.

Furthermore, delay typically retards the acquisition of a response as well as disrupting performance (see the excellent review by Renner, 1964). This disruption was illustrated in a recent study by Azzi, Fix, Keller, \& Rocha E Silva (1964), which showed that rats trained on a CRF schedule responded at a lower rate under conditions of delayed reinforcement, even though the delay was gradually introduced.

Delay in reinforcement also disrupts behavior maintained by schedules of intermittent reinforcement. For example, Pierce, Hanford, \& Zimmerman (1972) trained rats on a variable-interval schedule and found that a delay in reinforcement produced lower response rates and longer pauses after reinforcement (PARs). Studies that have employed a fixed-ratio (FR) schedule (Ferster \& Hammar, 1965; Morgan, 1972) have also found disruption of performance under conditions of delayed reinforcement. Ferster and Hammar found that although the responding of Rhesus monkeys was maintained with a 24-h delay, it was considerably weakened, as evidenced by longer PARs. Similarly, Morgan (1972), using rats, found longer PARs under conditions of delayed reinforcement. In addition, Morgan measured "work time," defined as the time elapsed from the end of the PAR, which is denoted by

*This research was supported in part by BSSG Grant 5-S05-RR-07127-03 to the second author. This paper was sponsored by Henry A. Cross, who takes full editorial responsibility. the first response of the ratio, to the completion of the ratio, denoted by the last response before reinforcement. The effect of delay upon work time was not consistent: Delay increased work time in some Ss and decreased it in others. Mean work time and mean PAR seem to be appropriate measures of the effect of delayed reinforcement. Another apt measure would be variability, which has seldom been reported.

Research has shown that behavior becomes more variable during the course of extinction (Skinner, 1938; Frick \& Miller, 1951), and, since a delay in reinforcement, especially a relatively long one, is similar to extinction for the animal, it should also affect the variability of performance.

The present study was designed to assess the effects of a delay in reinforcement upon a pigeon's performance under an FR schedule. The dependent measures were PAR and work time, and the mean and standard deviation (SD) were chosen as measures of the absolute level of behavior and the variability of behavior, respectively.

\section{METHOD \\ Subjects}

A female White Carneaux pigeon, obtained from the Palmetto Pigeon Plant, served as the S. The bird was an experimentally naive adult and was maintained at approximately $80 \%$ of its free-feeding weight throughout the experiment.

\section{Apparatus}

Only the center key of a Lehigh Valley Model 1519-D operant conditioning chamber was used, the other two keys being covered with tape. In addition to the standard houselight above the center key, a houselight was mounted above each of the side keys. A red pilot light was located at the back of the chamber. Throughout the experiment, the reinforcer was $1.5 \mathrm{sec}$ access to a magazine loaded with mixed grain; this duration was controlled by a timer that started when the bird's head broke the beam of the photocell located in the food magazine. Electromechanical equipment, which programmed the experimental contingencies, was located in an adjacent room.

\section{Procedure}

During the first three sessions, the bird was trained by the method of successive approximations to peck the key, which was illuminated by an orange light, except during reinforcement. Then $S$ received two sessions of CRF. During the next five sessions, the response requirement was gradually increased until the bird performed 50 responses to obtain a reinforcer (FR 50). Once the keypeck was acquired, all sessions were terminated after $S$ received 64 reinforcers. The bird received 35 sessions of training under an FR 50 schedule with no delay in effect; within-session data taken the last 5 days showed that S's performance was stable. During Sessions 46-55, a 2.5-sec delay in reinforcement was in effect, a 5-sec delay during Sessions 56-63, and a 15-sec delay in Sessions 64-74. At the 75th session, the duration of the reinforcement delay was increased to $30 \mathrm{sec}$, which remained in effect for the final 44 sessions. 


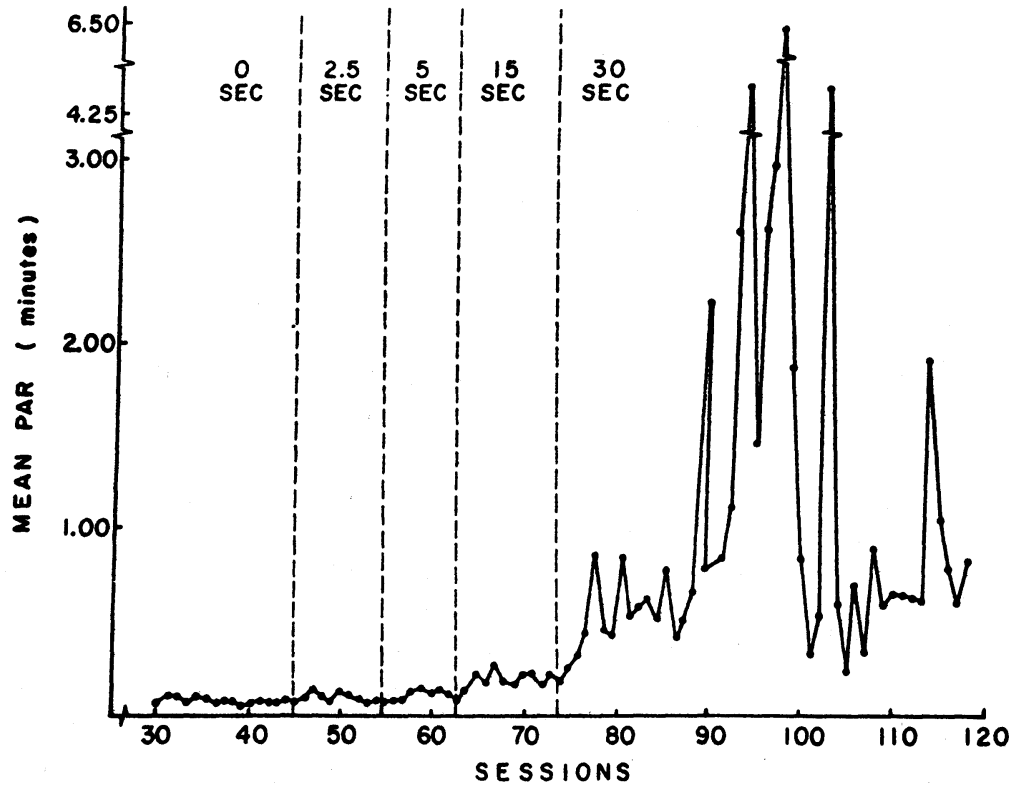

During Sessions 46-50, the sequence for the bird was: onset of key light, 50 pecks, the delay period accompanied by offset of key light, the reinforcer, and, finally, the return of the key light. During Sessions 51-119, the sequence was: onset of key light, 50 pecks, the delay period accompanied by offset of key light and houselights and onset of the red pilot light, presentation of the reinforcer, and, finally, the return of the key light. Responses during the delay had no scheduled consequences.

For each session, mean PAR and mean work time were recorded. In addition, for most sessions within-session data was recorded so that variability could be calculated.

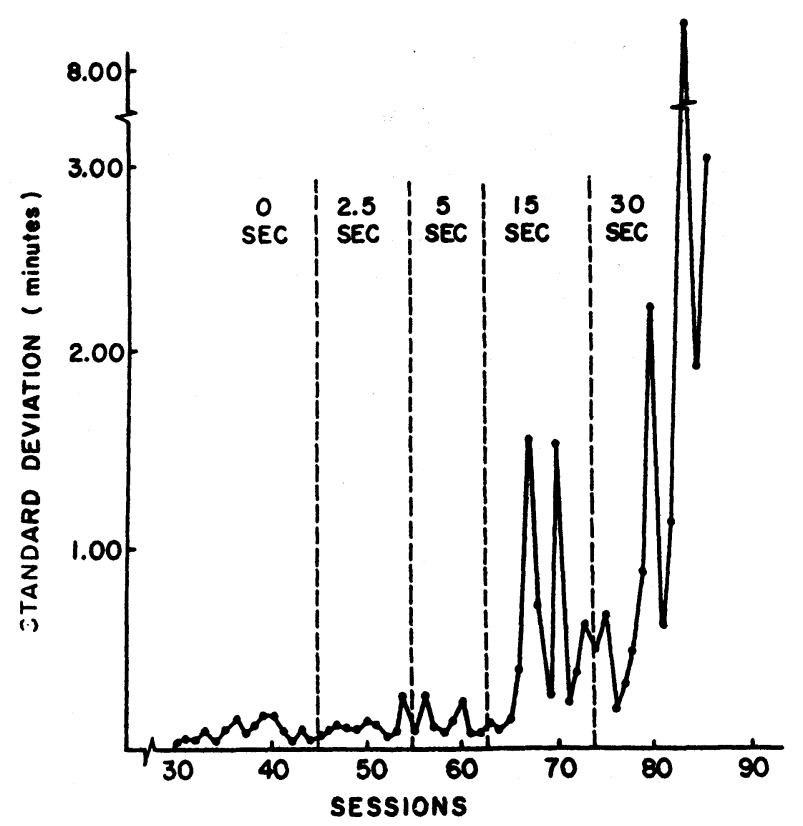

Fig. 2. Standard deviation of PAR as a function of reinforcement delay. Dashed lines indicate changes in the duration of the delay.
Fig. 1. Mean PAR as a function of reinforcement delay. Dashed lines indicate changes in the duration of the delay.
Fixed-ratio performance was stable under conditions of immediate reinforcement. The mean work time was about $.32 \mathrm{~min}$, while PAR averaged $.07 \mathrm{~min}$. Standard deviations were also small, under .10 in most cases. With the introduction of the $2.5-\mathrm{sec}$ and 5 -sec delays, performance remained stable. With a delay of $15 \mathrm{sec}$, there was a slight increase in variability of PAR, so that SD averaged about .14. The introduction of a 30-sec delay dramatically increased PAR. Figure 1 shows the mean PAR throughout the experiment and the effect of the 30-sec delay can be seen clearly. A delay of $30 \mathrm{sec}$ also increased the SD of PAR, as shown in Fig. 2. Within a session, the pauses were generally longer than pauses under the shorter delays and there were some extremely long pauses (e.g., $22 \mathrm{~min}$ ); thus, the mean and SD were elevated.

Delay of reinforcement had a similar effect upon work time. Figure 3 shows little change in mean work time prior to the introduction of the 30-sec delay, which produced a sharp increase that was maintained throughout the experiment. Figure 4 shows that the $30-\mathrm{sec}$ delay also increased the variability of this measure. While recording the work-time data within the sessions, it was noted that responding usually occurred in "bursts" so that the bird would go for a period, perhaps several minutes, without making a response, and then it might make several in rapid succession.

Casual observations of S's behavior showed that during the 2.5-, 5-, and 15-sec delays, the bird often pecked the key, although not at a high rate, during the delay period. The bird would typically sit during the $30-\sec$ delay. Cooing, wing flapping, and turning away from the key sometimes occurred during the delay and the PAR, and preening was occasionally observed during PAR. Cooing, wing flapping, and turning away from the 
Fig. 3. Mean work time as a function of reinforcement delay. Dashed lines indicate changes in the duration of the delay.

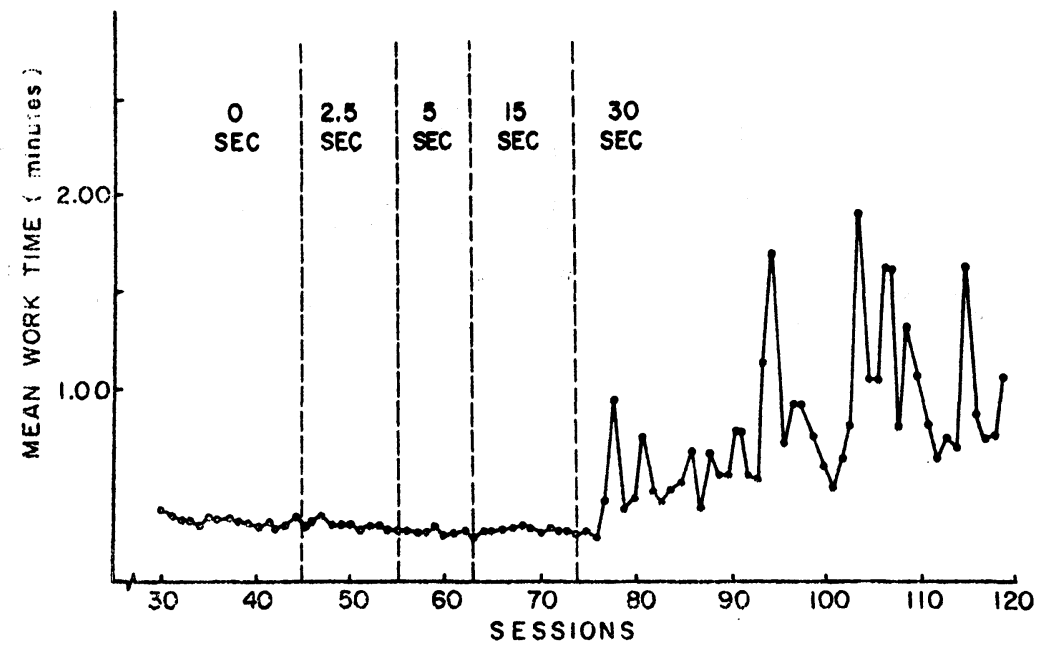

key also occurred during the work time, but not as often as during delay and PAR periods.

\section{DISCUSSION}

In the present study, introduction of a delay in reinforcement disrupted the performance maintained by an FR schedule. For example, it took the bird as long as $4 \mathrm{~h}$, not counting delay periods, to obtain 64 reinforcers under a 30 -sec delay, whereas these were obtained in about $45 \mathrm{~min}$ under conditions of no delay. More specifically, the mean PAR increased markedly when the delay was 30 sec. This increase in PAR is consistent with the previous research with nonhuman primates (Ferster \& Hammar, 1965) and rats (Azzi et al, 1964; Morgan, 1972; Pierce et al, 1972).

Work time of the bird also increased with the introduction of the 30-sec delay. Morgan (1972) found that delayed reinforcement increased work time in some Ss and decreased it in others. These individual differences were not explored in the present study, which used only one S. Further research is needed to ascertain the variables, e.g., species differences, ratio size, reinforcement magnitude, etc., that determine the effect of delay upon work time.

The increased variability of the PAR and the work time provides evidence about the relationship between delayed reinforcement and extinction. To the extent that delay gives the animal the experience of nonreinforcement after a response, one might expect delay effects to be similar to extinction effects, such as those reported by Skinner (1938) and Frick \& Miller (1951). This expectation was confirmed in the present study by the increased variability in PAR and work time as well as in the other behaviors (cooing, turning away, preening, etc.).

These nonkeypecking behaviors during the delay and the PAR are similar to those observed during the negative stimulus component of discrimination training (Terrace, 1963) and may provide insight into the origins of the disruption of responding. The wing flapping, cooing, and preening may be behavioral indicators of some internal state of the organism, such as anger or frustration. This idea is consistent with Azrin's (1961) suggestion that "performance under a schedule of positive reinforcement may at certain stages be aversive in spite of the apparent absence of aversive stimuli [p. 383]." Additional evidence for the idea of aversive elements of positive schedules comes from the studies of schedule-induced aggression (e.g., Gentry, 1968; Richards \& Rilling, 1972). When pigeons are given the opportunity to attack a target bird, they do so primarily during the PAR, when working under a fixed-interval or a fixed-ratio schedule.

Another variable which, like delay, affects PAR is the ratio size. Felton \& Lyon (1966) reported that PAR increases as the

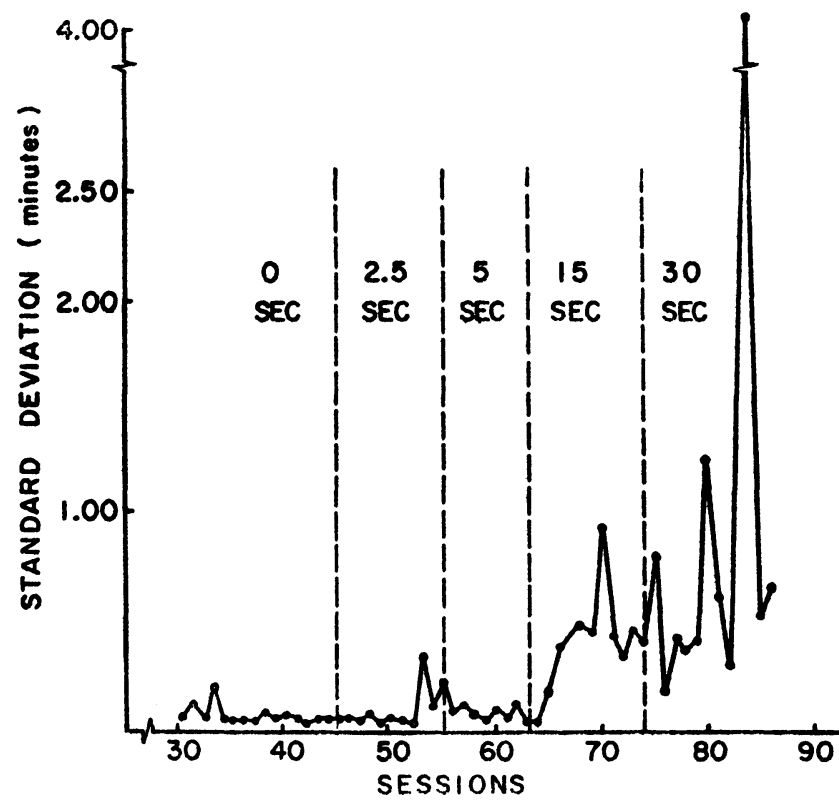

Fig. 4. Standard deviation of work time as a function of reinforcement delay. Dashed lines indicate changes in the duration of the delay.

ratio becomes larger. They also reported response rate, which corresponds to work time and, as in delay experiments, found no reliable trend. Thus, the effects of delay are similar in some ways to extinction (Skinner, 1938; Frick \& Miller, 1951), presentation of a negative stimulus during discrimination training (Terrace, 1963), increasing a ratio requirement (Felton \& Lyon, 1966), and even certain stages of a regular FR schedule (Azrin, 1961).

Finally, another possible explanation for the disruption of the operant response involves accidental reinforcement of competing responses. It has already been stated that other behaviors were emitted during the delay period. Since a long delay has the effect of reinforcing whatever the animal happens to be doing prior to the delivery of the reinforcement, it seems probable that some of these other behaviors were reinforced.

\section{REFERENCES}

Azrin, N. H. Timeout from positive reinforcement. Science, $1961,133,382-383$

Azzi, R., Fix, D. R., Keller, F., \& Rocha E Silva, M. Exteroceptive control of response under delayed 
reinforcements. Journal of the Experimental Analysis of Behavior, 1964, 7, 159-164.

Felton, M., \& Lyon, D. O. The post-reinforcement pause. Journal of the Experimental Analysis of Behavior, 1966, 9, 131-134.

Ferster, C. B. Sustained behavior under delayed reinforcement. Journal of Experimental Psychology, 1953, 45, 218-224.

Ferster, C. B., \& Hammar, C. Variables determining the effects of delay in reinforcement. Journal of the Experimental Analysis of Behavior, 1965, 8, 243-254.

Frick, F. C., \& Miller, G. A. A statistical description of operant conditioning. American Journal of Psychology, 1951, 64, 20-36.

Gentry, W. Fixed-ratio schedule-induced aggression. Journal of the Experimental Analysis of Behavior, 1968, 11, 813-817.

Morgan, M. J. Fixed-ratio performance under conditions of delayed reinforcement. Journal of the Experimental Analysis of Behavior, 1972, 17, 95-97.

Pierce, C. H., Hanford, P. V., \& Zimmerman, J. Effects of different delay of reinforcement procedures on variable-interval responding. Journal of the Experimental Analysis of Behavior, 1972, 18, 141-146.

Renner, K. E. Delay of reinforcement: A historical review. Psychological Bulletin, 1964, 61, 341-361

Richards, R. W., \& Rilling, M. Aversive aspects of a fixed-interval schedule of food reinforcement. Journal of the Experimental Analysis of Behavior, 1972, 17, 405-411.

Skinner, B. F. The behavior of organisms. New York: A ppleton-Century-Crofts, 1938.

Terrace, H. S. Discrimination learning with and without "errors." Journal of the Experimental Analysis of Behavior, $1963,6,1-27$.

(Received for publication September 22, 1972.) 